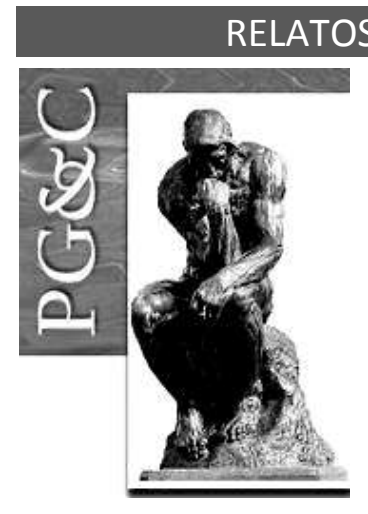

\title{
CRIAÇÃO DO CONHECIMENTO ORGANIZACIONAL BASEADA NOS CAPACITADORES DE VON KROGH, NONAKA E ICHIJO: ESTUDO DE CASO
}

\author{
Frederico Cesar Mafra Pereira \\ Doutor em Ciência da Informação pela Universidade Federal de Minas \\ Gerais, Brasil. Professor da Fundação Pedro Leopoldo, Brasil. \\ E-mail: professorfrederico@yahoo.com.br \\ Elizângela Freitas da Silva \\ Mestre em Administração pela Fundação Pedro Leopoldo, Brasil. \\ Professora da Universidade do Estado de Minas Gerais, Brasil. \\ E-mail: elis freitass@hotmail.com
}

\begin{abstract}
Resumo
Esta pesquisa tem como objetivo identificar e analisar quais capacitadores para a criação do conhecimento organizacional estão presentes na Granja de Suinocultura DF Pork, localizada no município de Faria Lemos, em Minas Gerais (Brasil), com base nas perspectivas de seus gestores e colaboradores. A pesquisa se caracteriza como do tipo descritiva, de caráter qualitativo, tendo o estudo de caso como o método escolhido, sendo entrevistados nove sujeitos representativos dos níveis estratégico, gerencial e operacional da empresa, selecionados através de amostra por conveniência, via roteiro semiestruturado, além do uso da técnica de observação participante. Os resultados obtidos apontam a existência de quatro capacitadores propostos por Von Krogh et al. (2001) no contexto da DF Pork: 'instilar a visão do conhecimento', 'gerenciar as conversas', 'criar o contexto adequado' e 'globalizar o conhecimento local', sendo detectada a inexistência do capacitador 'mobilizar os ativistas do conhecimento'. Entretanto, a existência desses capacitadores acontece no nível dos indivíduos da empresa pesquisada, por meio de práticas de conversão do conhecimento isoladas, e não como condições para a criação do conhecimento em nível organizacional. Tais considerações podem servir de base para a estruturação e implementação de práticas de conversão do conhecimento em nível organizacional na DF Pork.
\end{abstract}

Palavras-Chave: Gestão do Conhecimento. Capacitadores para o Conhecimento. Criação do Conhecimento.

\section{CREATION OF ORGANIZATIONAL KNOWLEDGE ON THE BASIS VON KROGH, NONAKA E ICHIJO CAPACITORS: CASE STUDY}

\begin{abstract}
This research aimed to identify and analyze what enablers are present at the creation of organizational knowledge of the swine Granja DF Pork, located in the Faria Lemos, Minas Gerais (Brazil), from the perspectives of its managers and employees. The research is characterized as descriptive, qualitative, and the case study as the chosen method. There were nine representative interviewed subjects of strategic, managerial and operational company, selected by convenience sample, via semi-structured, and the use of participant observation technique. The results indicate the existence of four enablers proposed by Von Krogh et al. (2001) in the context of DF Pork: 'to instill the vision of knowledge', 'managing conversations', 'creating the appropriate context' and 'globalize local knowledge', and detected the absence of enabling 'mobilize knowledge activists'. However, the existence of these enablers happens at the level of individuals the company researched through isolated knowledge conversion practices, not as conditions for the creation of knowledge at the organizational level. Such
\end{abstract}

Perspectivas em Gestão \& Conhecimento, João Pessoa, v. 8, n. 1, p. 20-43, jan./abr. 2018. DOI: http://dx.doi.org/10.21714/2236-417X2018v8n1p20

http://periodicos.ufpb.br/ojs2/index.php/pgc. ISSN: 2236-417X. Publicação sob Licença (cc) EY-NC-ND 
considerations may serve as a basis for structuring and implementation of knowledge translation practices at the organizational level in DF Pork.

Keywords: Knowledge Management. Enablers for Knowledge Management. Creation of Knowledge.

\section{INTRODUÇÃO}

Na busca pela excelência empresarial e maior competitividade, muitas organizações já perceberam e compreenderam que o capital humano não representa apenas um conjunto de pessoas executando suas tarefas, mas sim um recurso que pode ser desenvolvido, valorado e medido como qualquer outro recurso organizacional. Nesse sentido, o conhecimento humano assume a posição de principal fonte de vantagem competitiva para as empresas, conduzindo a uma série de mudanças organizacionais que possibilitam a criação e o compartilhamento do conhecimento por meio da adequação do ambiente e, principalmente, pela mudança de comportamento dos líderes e dos colaboradores (NONAKA; TAKEUCHI, 1997).

Da Silva (2004) e Mafra Pereira (2005) argumentam que a partir da década de 1990 as empresas passaram a dar mais atenção aos ativos intangíveis (como marcas, ideias, processos, conhecimento interno, etc.), sendo estes de difícil imitação por parte de concorrentes (FLEURY; OLIVEIRA, 2001), podendo, então, ser fonte de ampliação de receitas e capacidade inovadora. Portanto, conforme afirma Angeloni (2002), a atualidade e a correta aplicação do conhecimento, pelos gestores e empregados de uma organização, auxiliam na formulação de estratégias competitivas e na tomada de decisões gerenciais. Esse novo cenário passa, necessariamente, pela compreensão da Gestão do Conhecimento, cuja proposta de identificação, maximização, codificação e compartilhamentos de conhecimentos estrategicamente relevantes nas organizações (TERRA, 2001) acabam por criar uma disposição favorável para o aprendizado constante e a valorização do capital intelectual.

Conforme Scharf (2007, p. 93), "a Gestão do Conhecimento compreende um conjunto de processos para a criação, disseminação e uso do conhecimento dentro da empresa, com objetivo de desenvolver vantagens competitivas sustentáveis". Corroborando Scharf (2007), Gonçalves (2010) defende que o conhecimento transformado em inovação é um dos mais importantes recursos para se garantir vantagens competitivas sustentáveis aos agentes econômicos no cenário contemporâneo. Por conseguinte, gerenciar os ativos intelectuais tornou-se imperativo. Esses ativos são valiosos, difíceis de serem mensurados e se constituem, na atualidade, em um dos maiores patrimônios organizacionais. Portanto, não é qualquer exagero dizer que o conhecimento é o recurso mais importante de que uma organização dispõe na nova economia baseada em conhecimento.

Entretanto, a organização não pode criar conhecimento sozinha e, por isso, depende da iniciativa dos indivíduos e da interação que acontece dentro do grupo, segundo afirmam Nonaka e Takeuchi (1997). Normalmente é a partir do domínio do conhecimento interno que as empresas se mantêm seguras e operantes, com adoção e compartilhamentos das melhores práticas, alocação das pessoas certas, mesmo com o advento de alguma movimentação como saída espontânea ou motivada de empregados, conhecimentos-chave das mesmas, desenvolvimento do treinamento corporativo, monitoramento do ambiente de negócios e gerenciamento da cadeia de suprimentos.

Nonaka e Takeuchi (1997) destacam que cabe às empresas criar o ambiente organizacional adequado à promoção do conhecimento, o chamado ba ou contexto capacitante. Santos (2004) aponta alguns desafios bastante exigentes que as empresas precisam responder para favorecerem o compartilhamento de conhecimento, como o desenvolvimento das competências humanas internas, a criação de ambientes que estimulem

Perspectivas em Gestão \& Conhecimento, João Pessoa, v. 8, n. 1, p. 20-43, jan./abr. 2018. 
a aprendizagem, a gestão adequada de pessoas e o estímulo ao desenvolvimento de comunidades virtuais. A criação dessa ambiência favorável à troca, ampliação e disseminação do conhecimento e do aprendizado é referendada por Von Krogh et al. (2001) e Choo (2006).

Em especial, Von Krogh et al. (2001) destacam que se deve apoiar o contexto capacitante, comprometendo-se com as ideias e experiências pessoais internas aos grupos, agindo como catalisadores da criação do conhecimento organizacional. Para isso, consideram a existência de cinco capacitadores que influenciam intensamente no processo de criação de conhecimento organizacional, sendo eles: a) Instilar a visão do conhecimento; b) Gerenciar as conversas; c) Mobilizar os ativistas do conhecimento; d) Criar o contexto adequado; e) Globalizar o conhecimento local. Diversos estudos identificados na literatura se utilizaram do modelo de Von Krogh et al. (2001) para o estudo sobre o contexto capacitante e seus capacitadores, como Braga et al. (2013), Carvalho Jr. et al. (2013), Silva (2013), Gomes (2014) e Pereira (2014), e os mesmos foram também utilizados como referência para a realização deste trabalho.

Portanto, o objetivo deste estudo foi identificar e analisar, sob a ótica de Von krogh et al. (2001), quais capacitadores estão presentes na criação do conhecimento organizacional da Granja de Suinocultura DF Pork, localizada no município de Faria Lemos, em Minas Gerais (Brasil). A escolha por estudar o setor suinícola na Zona da Mata Mineira e, em especial, a Granja de Suinocultura Duduta Ferreira Pork (DF Pork), localizada na cidade de Faria Lemos, se justifica por vários motivos. Em primeiro lugar, desde os anos de 1980 a suinocultura na Zona da Mata Mineira iniciou um processo de crescimento, tornando o mercado também mais competitivo, dada a incorporação e implantação de novas técnicas de nutrição, manejo, instalações e produção genética. Assim, as inovações tecnológicas, a modernização do processo produtivo e o conhecimento organizacional passaram a ser aliados na gestão de uma granja de suinocultura. Em consequência, este estudo pode contribuir para a melhoria dos processos referentes à Gestão do Conhecimento na granja DF Pork, a partir dos capacitadores propostos por Von Krogh et al. (2001). Em terceiro lugar, este estudo contribuiu para a academia, ampliando o arcabouço teórico-empírico de um tema que tem ganhado representatividade nos campos da Administração e da Ciência da Informação, em especial. Por último, o trabalho pode, efetivamente, contribuir na sugestão e implementação de melhorias nos processos voltados à criação e gestão do conhecimento em nível organizacional.

\section{REFERENCIAL TEÓRICO}

Segundo Alvarenga Neto (2005), as definições de dado, informação e conhecimento se constituem no marco teórico conceitual no qual estão baseadas formulações, proposições e discussões relativas às organizações do conhecimento e à Gestão da Informação e do Conhecimento.

Conforme Davenport e Prusak (2003), os dados são um conjunto de fatos distintos e objetivos, relativos a eventos. No âmbito organizacional, são utilitariamente descritos como registros estruturados de transações. De outra forma, é o registro estruturado do que aconteceu na organização, não envolvendo juízos de valor ou interpretações para a tomada de decisões.

Para Setzer (1999) dado é uma sequência de símbolos quantificados e quantificáveis desprovidos de significado, independentemente de contexto e de assimilação por parte dos usuários. Já a informação é definida por este autor como um dado ao qual se atribuem significado e contexto, pressupõe assimilação e entendimento pelo receptor. Segundo Davenport e Prusak (2003), a informação tem por finalidade mudar o modo como o destinatário vê algo, exercer algum impacto sobre seu julgamento e comportamento. Assim, "o significado original da palavra 'informar' é 'dar forma a', sendo que a informação visa a

Perspectivas em Gestão \& Conhecimento, João Pessoa, v. 8, n. 1, p. 20-43, jan./abr. 2018. 
modelar a pessoa que a recebe no sentido de fazer alguma diferença em sua perspectiva ou insight" (DAVENPORT; PRUSAK, 2003, p. 4).

Com relação ao conhecimento, este é considerado algo mais profundo que dados e informação, no entendimento de Davenport e Prusak:

Conhecimento é uma mistura fluida de experiência condensada, valores, informação contextual e insight experimentado, a qual proporciona uma estrutura para a avaliação e incorporação de novas experiências e informações. Ele tem origem e é aplicado na mente dos conhecedores. Nas organizações, ele costuma estar embutido não só em repositórios, mas também em rotinas, processos e normas organizacionais (DAVENPORT; PRUSAK, 2003, p. 6).

Ou seja, diferentemente de dados e informações, o conhecimento contém discernimento. Ele pode julgar novas situações e informações à luz daquilo que já é conhecido e julgar a si mesmo e se aprimorar em resposta a novas situações e informações (DAVENPORT; PRUSAK, 2003). Ainda de acordo com estes autores, dado, informação e conhecimento não são sinônimos. O sucesso ou o fracasso organizacional muitas vezes pode depender de se saber de qual deles a empresa necessita, com qual deles pode contar e o que pode ou não ser feito com cada um deles. Entender o que são esses três elementos e como passar de um para outro é essencial para a realização bem-sucedida do trabalho ligado ao conhecimento.

Portanto, o conhecimento deriva da informação da mesma forma que a informação deriva de dados, e para que uma informação se transforme em conhecimento são necessárias:

a) Comparação: de que forma as informações relativas a essa situação se compram a outras situações conhecidas?

b) Consequências: que implicações essas informações trazem para as decisões e tomadas de ação?

c) Conexões: quais as relações desse novo conhecimento com o conhecimento já acumulado?

d) Conversação: o que as outras pessoas pensam dessa informação?

Na concepção de Choo (2006), o conhecimento tácito é o conhecimento pessoal usado pelos membros da organização para realizar seu trabalho e dar sentido ao seu mundo, sendo de difícil formalização e comunicação, por ser expresso por habilidades que estão baseadas em ações. Não pode, portanto, ser reduzido a regras. Sua aprendizagem se dá por longos períodos de experiência e de execução de uma tarefa, durante os quais o indivíduo desenvolve capacidade para fazer julgamentos intuitivos sobre a realização bem-sucedida da atividade. Em contrapartida, o conhecimento explícito é definido como aquele que pode ser expresso formalmente por meio da utilização de um sistema de símbolos, podendo ser facilmente codificado e difundido. O conhecimento, portanto, baseia-se em dados e informações, mas, ao contrário deles, está sempre ligado a pessoas. Ele é construído por indivíduos e representa suas crenças sobre relacionamentos causais (PROBST; RAUB; ROMHARDT, 2002).

\subsection{Gestão do Conhecimento}

Diante do desafio de gerenciar o conhecimento organizacional, estruturá-lo e sistematizá-lo de modo a atingir objetivos e metas institucionais e obter vantagens competitivas, ocorre o processo de Gestão do Conhecimento. Para Buoro, Oliva e Santos (2007), são inúmeros os benefícios oriundos desse tipo de processo, como organizar a

Perspectivas em Gestão \& Conhecimento, João Pessoa, v. 8, n. 1, p. 20-43, jan./abr. 2018. 
informação disponível, mapear competências individuais, acelerar a informação, entre outros. No entanto, os autores afirmam que, apesar desses benefícios, a Gestão do Conhecimento representa uma tarefa extremamente desafiadora e complexa.

Conforme afirma Kuniyoshi (2008, p. 37):

Ela surge para intermediar o processo de capacitação corporativo e atender à necessidade de responder aos desafios do gerenciamento de uma empresa inserida em um ambiente complexo, extremamente competitivo e com o seu interior sobrecarregado de informação. (KUNIYOSHI, 2008, p. 37)

Reis (2005) reconhece que a Gestão do Conhecimento é tida como elemento propulsor de mudanças no comportamento dos indivíduos, pois estimula o compartilhamento intensivo de experiências e competências e do gerenciamento dos estoques informacionais, visando à criação de conhecimentos que servem de base para as ações organizacionais e asseguram a sobrevivência da organização dentro dos parâmetros atuais.

Uma gestão voltada para o conhecimento é aquela capaz de estabelecer uma visão estratégica para o uso da informação e do conhecimento (ALVARENGA NETO, 2005). O autor sustenta que promover a aquisição, a criação, a codificação parcial e a transferência de conhecimentos tácitos e explícitos estimula a criatividade, a inovação e a aprendizagem, além da educação continuada. E também possui a capacidade para propiciar um contexto organizacional adequado, reconhecendo o papel fundamental da cultura organizacional, das pessoas, seus comportamentos e atitudes em um cenário em que a informação e o conhecimento são tidos como os únicos fatores capazes de fortalecer as competências essenciais das organizações e contribuir para a consolidação de vantagens competitivas sustentáveis.

Quadro 1 - Definições de Gestão do Conhecimento

\begin{tabular}{|l|l|}
\hline \multicolumn{1}{|c|}{ Autores } & \multicolumn{1}{c|}{ Definições de GC } \\
\hline Sveiby (1997) & GC é a arte de criar valor através da alavancagem dos ativos intangíveis. \\
\hline $\begin{array}{l}\text { Liebowitz e Wilcox } \\
\text { (1997) }\end{array}$ & $\begin{array}{l}\text { Consiste na habilidade que as organizações têm para gerenciar } \\
\text { conhecimento, armazená-lo, agregar valor e distribui-lo. }\end{array}$ \\
\hline O`Leary (1998) & $\begin{array}{l}\text { É o gerenciamento do conhecimento com o intuito de facilitar sua criação, } \\
\text { possibilitar acessá-lo e reutilizá-lo. }\end{array}$ \\
\hline Bassi (1999) & $\begin{array}{l}\text { É o processo de criação, captura e utilização do conhecimento com o objetivo } \\
\text { de melhorar o desempenho organizacional. }\end{array}$ \\
\hline $\begin{array}{l}\text { Bukowitz e Willians } \\
\text { (2002) }\end{array}$ & $\begin{array}{l}\text { Processo pelo qual a organização gera riqueza, a partir do seu conhecimento } \\
\text { ou capital intelectual. }\end{array}$ \\
\hline Cianconi (2003) & $\begin{array}{l}\text { Pode ser vista como um processo amplo de criação, uso e disseminação do } \\
\text { conhecimento na empresa. A GC se traduz numa série de práticas } \\
\text { facilitadoras do compartilhamento do conhecimento na empresa, tanto sobre } \\
\text { seus processos internos quanto sobre seus clientes e seu ambiente } \\
\text { competitivo. [...] o que vem sendo considerado como GC é, sobretudo, uma } \\
\text { tentativa de facilitar e criar melhores condições para a comunicação entre } \\
\text { indivíduos, além de estimular, categorizar e formalizar as atividades de } \\
\text { compartilhamento de experiências, a busca por codificar e explicitar o tácito, } \\
\text { de promover o aprendizado permanente e continuado dos indivíduos nas } \\
\text { organizações. }\end{array}$ \\
\hline Salojärvi, (2005) & $\begin{array}{l}\text { GC é uma perspectiva sobre a gestão da empresa como um todo, englobando } \\
\text { atividades em todas as áreas gerenciais relevantes. }\end{array}$ \\
\hline Dalkir (2005) & $\begin{array}{l}\text { Coordenação deliberada e sistemática de pessoas, tecnologias, processos e } \\
\text { estrutura de uma organização com o objetivo de adicionar valor por meio do } \\
\text { reuso e da inovação. }\end{array}$ \\
\hline
\end{tabular}

Perspectivas em Gestão \& Conhecimento, João Pessoa, v. 8, n. 1, p. 20-43, jan./abr. 2018. 


\begin{tabular}{|l|l|}
\hline Logan (2006) & $\begin{array}{l}\text { A GC não existe sem a colaboração, o que definimos como "o coração do } \\
\text { modelo de processo GC". Acreditamos também que a GC não é uma classe } \\
\text { separada da tecnologia. Em vez disso, usa muitas categorias de tecnologia, } \\
\text { quase nenhuma das quais são exclusivas para GC. Por exemplo, a partilha de } \\
\text { conhecimento faz uso de tecnologias de gerenciamento de conteúdo para } \\
\text { realizar os processos de GC de captura, organização e acesso ao } \\
\text { conhecimento. }\end{array}$ \\
\hline Uriarte Jr (2008) & $\begin{array}{l}\text { É o processo pelo qual organizações geram valor de seus ativos intelectuais e } \\
\text { base de conhecimento, que possui processos de identificação, aquisição, } \\
\text { distribuição e manutenção do conhecimento essencial para organização. }\end{array}$ \\
\hline Omerzel (2010) & $\begin{array}{l}\text { GC faz parte do processo de gestão da empresa como um todo, e engloba } \\
\text { análises sistemáticas, planejamento,aquisição, criação, desenvolvimento, } \\
\text { armazenamento e uso do conhecimento nas empresas. Ela se concentra no } \\
\text { indivíduo e no seu conhecimento como um recurso e valor. }\end{array}$ \\
\hline Jennex (2014) & $\begin{array}{l}\text { GC é um ciclo de aquisição de conhecimentos, armazenamento, avaliação, } \\
\text { disseminação e aplicação. }\end{array}$ \\
\hline Fialho (2014) & $\begin{array}{l}\text { A GC visa a sustentação do processo de decisão nos diversos níveis da } \\
\text { organização. }\end{array}$ \\
\hline $\begin{array}{l}\text { Varela; Babosa; Farias } \\
\text { (2015) }\end{array}$ & \begin{tabular}{l} 
A GC integra informação, processos, pessoas e recursos. \\
\hline Willerding; Krause; \\
Lapolli (2016)
\end{tabular} \\
\hline
\end{tabular}

Fonte: Elaborado e atualizado pelos autores, com base em Trindade et al. (2016), Bezerra e Guimarães (2017) e Beira et al. (2017)

A Gestão do Conhecimento, como realça Stewart (1998), propicia o conceito de capital intelectual. Segundo ele, o capital intelectual constitui a matéria intelectual (conhecimento, informação, propriedade intelectual, experiência) que pode ser utilizada para gerar riqueza. É a capacidade mental coletiva. É difícil identificá-lo e mais difícil ainda distribuí-lo de forma eficaz. $O$ autor também considera que o capital intelectual pode ser encontrado nas pessoas, nas estruturas e nos clientes, mas também enfatiza que "o capital intelectual não é criado a partir de partes distintas do capital humano, estrutural e do cliente, mas do intercâmbio entre eles" (STEWART, 1998, p. 70).

E Bukowitz e Willians (2002, p. 18) complementam que:

A definição de Gestão do Conhecimento exige outra - a de capital intelectual ou do conhecimento, que é qualquer coisa valorizada pela organização que esteja contida nas pessoas, ou seja, derivada de processos, de sistemas e da cultura organizacional - conhecimento e habilidades individuais, normas e valores, bases de dados, metodologia, software, knowhow, licenças, marcas, segredos comerciais (BUKOWITZ; WILLIANS, 2002, p. 18).

\subsection{Criação do Conhecimento Organizacional}

Segundo Alvarenga Neto (2008), a criação do conhecimento nas organizações é feita a partir de crenças verdadeiras e justificadas. Portanto, o conhecimento, ao ser criado, está carregado de crenças pessoais. Nesse caso, é imperativo que as organizações mantenham constantes investimentos que passam pela manutenção de excelente clima organizacional, por adequadas políticas de atração e retenção de talentos, pelo contínuo desenvolvimento dos colaboradores, chamado também de educação continuada, e por remuneração adequada e estimulante para todos. Vasconcelos e Ferreira (2002, p. 127) afirmam:

Perspectivas em Gestão \& Conhecimento, João Pessoa, v. 8, n. 1, p. 20-43, jan./abr. 2018. 
Hoje, os executivos estão preocupados em transformar as empresas em ótimos lugares para se trabalhar, de forma a gerar nos empregados um clima de orgulho tanto em relação ao trabalho que fazem quanto em relação à empresa na qual trabalham (VASCONCELOS; FERREIRA, 2002, p. 127).

Para Nonaka e Takeuchi (1997), conhecimento organizacional é a capacidade da empresa em criar novo conhecimento, difundi-lo na organização como um todo e incorporá-lo a produtos, serviços e sistemas. A construção do conhecimento, segundo esses autores, é alcançada quando existe uma sinergia na relação do conhecimento tácito com o conhecimento explícito, apresentando quatro processos de criação de conhecimento, a saber: socialização, combinação, internalização e externalização.

O conteúdo do conhecimento criado por cada forma de conversão difere dos demais, sendo o da socialização o "conhecimento compartilhado", o da externalização, o "conhecimento conceitual", o da combinação, o "conhecimento sistêmico", e o da internalização, o "conhecimento operacional" (PEREIRA, 2014, p. 51).

Assim, as quatro etapas da conversão do conhecimento de Nonaka e Takeuchi (1997) geram a Espiral do Conhecimento (Figura 1):

Figura 1 - A Espiral do Conhecimento

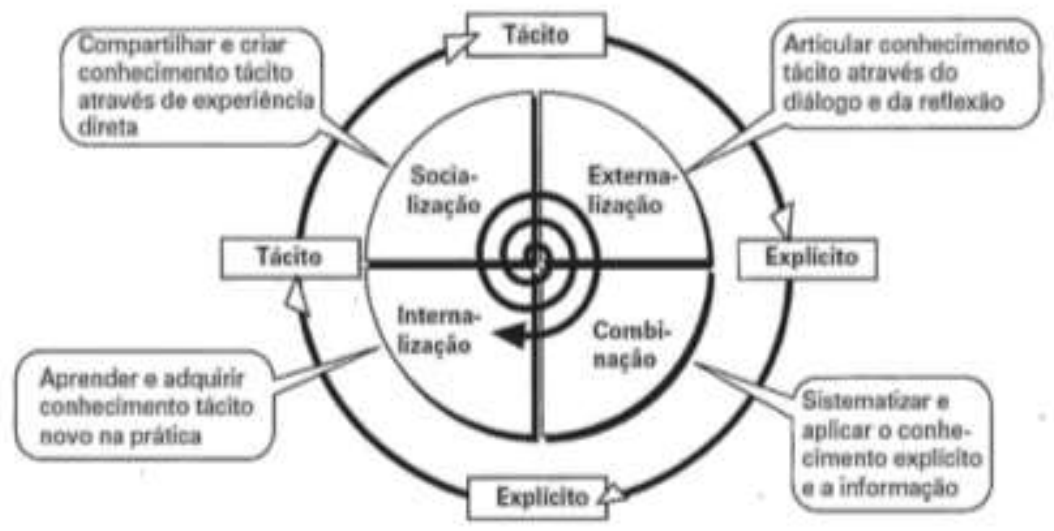

Fonte: Nonaka e Takeuchi (1997, p.80)

A partir da Espiral do Conhecimento, os ciclos de criação do conhecimento se reiniciam, aumentando sua amplitude. Segundo Nonaka e Takeuchi (1997, p. 82):

O conhecimento tácito mobilizado é ampliado organizacionalmente através dos quatro modos de conversão do conhecimento e cristalizado em níveis ontológicos superiores. Chamamos isso de espiral de conhecimento na qual a interação entre conhecimento tácito e conhecimento explícito terá uma escala cada vez maior na medida em que subirem os níveis ontológicos (NONAKA; TAKEUCHI, 1997, p. 82).

Pereira (2014, p. 51) complementa afirmando que:

A espiral do conhecimento é, então, o processo em que o conhecimento tácito individual mobilizado pela organização interage com o conhecimento explícito com base nos quatro modos de conversão do conhecimento e vai

Perspectivas em Gestão \& Conhecimento, João Pessoa, v. 8, n. 1, p. 20-43, jan./abr. 2018. 
se ampliando para escalas cada vez maiores, envolvendo outros níveis e setores (divisões, departamentos) da organização (PEREIRA, 2014, p. 51).

Portanto, os níveis de criação do conhecimento passam pelo conhecimento individual, grupal, organizacional e interorganizacional. Todo esse nível de criação do conhecimento organizacional é apresentado em uma estrutura conceitual básica que contém duas dimensões - epistemológica e ontológica - e que ocorre em forma de uma "espiral". Na dimensão ontológica, considera-se, em termos restritos, que o conhecimento só é criado por indivíduos. Obviamente que as empresas - pessoas jurídicas - não geram conhecimento "espontaneamente" e, por isso, precisam dos indivíduos, sejam eles empregados diretos ou não, para tal. Nesse caso, as organizações, mais que nunca, precisam investir nas pessoas, proporcionando ambiente propício para tal. A dimensão epistemológica é baseada na distinção feita por Michael Polanyi (1966, citado por NONAKA; TAKEUCHI, 1997), sendo necessário conhecer, entender e diferenciar o conhecimento tácito do conhecimento explícito. O primeiro é considerado mais pessoal e o outro codificado.

Vasconcelos (2000) destaca que o conhecimento tácito que não é compartilhado, formalizado ou comunicado, tem pouco valor para a empresa. O desafio das organizações consiste, portanto, em converter o conhecimento tácito em explícito, e que este possa promover a inovação e o desenvolvimento de novos produtos. Assim, a tarefa de gerir o conhecimento está longe de ser fácil. As organizações necessitam desenvolver instrumentos que propiciem o compartilhamento do conhecimento daqueles que o têm, disponham esse conhecimento de forma estruturada, além de mantê-lo ou aprimorá-lo.

O conhecimento organizacional é visto por Nakano e Fleury (2005) sob duas perspectivas: a primeira, denominada cognitiva, vê o conhecimento como um insumo, que, embora intangível e complexo, é passível de ser armazenado, combinado e reutilizado. Nessa perspectiva, a Gestão do Conhecimento Organizacional se aproxima da gestão do processo produtivo de um bem intangível. É a administração eficaz das atividades relativas à aquisição ou criação, à utilização e à manutenção de um ativo intangível. A segunda perspectiva é a construtivista, na qual o conhecimento organizacional não é apenas um bem intangível a ser mantido e utilizado, mas o próprio processo de criação, sendo o resultado da interação entre as pessoas. $\mathrm{O}$ conhecimento é construído a partir da relação entre indivíduos, é dependente de suas capacidades e de suas características pessoais, do âmbito e das formas de expressão escolhidas. O foco da Gestão do Conhecimento Organizacional, nessa segunda perspectiva, está na administração das pessoas, na necessidade da oferta de possibilidades de interação e na comunicação interpessoal.

\subsection{Os Capacitadores da Criação do Conhecimento de Von Krogh, Nonaka e Ichijo (2001)}

Gomes (2014) ressalta que ir além da GC é desenvolver na organização a capacitação para o conhecimento. O autor assevera que o modelo proposto por Von Krogh et al. (2001) fornece conceitos sobre a criação e a utilização do conhecimento nas organizações para se obter vantagem competitiva. Ao mesmo tempo, fornece abordagens práticas ou "orientações pragmáticas", para a eficaz criação do conhecimento. E "[...] ressaltam que a criação do contexto capacitante é 'condição fundamental para que o processo aconteça e o conhecimento seja gerado" (VON KROGH et al., 2001, p. 16).

As cinco fases da criação do conhecimento, segundo Von Krogh et al. (2001) são:

a) Compartilhamento do conhecimento tácito - é o processo de se disseminar conhecimentos (socialização). Assim, a socialização promove a motivação pela participação no grupo, a identificação com este e o senso de empenho pelo bem-estar 
deste. Dessa forma, o processo de trabalho conjunto ou socialização é beneficiado pelos insights de cada membro do grupo;

b) Criação de conceitos - quando o conhecimento tácito torna-se explícito (externalizado). É um processo criativo que utiliza analogias e metáforas como linguagem intermediária, associando imagens compreendidas com clareza para elucidar outras que são ainda abstratas. Assim, um conceito capta as nuanças tácitas do conhecimento, sendo identificável pelos membros do grupo que o criou;

c) Justificação de conceitos - é um processo de apresentação e julgamento do conceito a partir de diálogo aberto e críticas construtivas, cabendo sua reformulação e reapresentação da forma mais adequada, caso necessário. Assim, a organização e seus colaboradores fazem uma avaliação do conceito criado e desenvolvido internamente;

d) Construção de protótipos - protótipo é a forma tangível do conceito, materializando-o em um objeto ou uma oferta de serviço inicial, combinando outros conceitos, produtos, componentes e procedimentos já existentes com o novo conceito;

e) Nivelação do conhecimento - esta fase é o resultado final das quatro fases anteriores, podendo resultar em possível inovação de produto ou serviço ou em conhecimento bruto. Assim, mesmo que o processo não crie uma ideia viável, ele gera benefícios para a organização, como nivelamento e materialização de conhecimentos, por meio do protótipo, que atua também como inspiração para novos processos de criação de conhecimentos.

Von Krogh et al. (2001) apontam, portanto, a existência de cinco capacitadores que influenciam intensamente no processo de criação de conhecimento organizacional, assim desenvolvidos:

a) Instilar a visão do conhecimento - tornar nítida a visão corporativa para se aproveitar bem mais o conhecimento. Enfatiza a importância da criação de conhecimento como função organizacional e deve ser expressão do comprometimento do topo da hierarquia da empresa. Determina o tipo e o conteúdo de conhecimento a ser desenvolvido na empresa e orienta a busca desse conhecimento em certas áreas e a construção de estoques de conhecimento a serem utilizados para enfrentar futuros desafios;

b) Gerenciar as conversas - a fim de torná-las mais eficazes e motivadoras do compartilhamento de conhecimentos tácitos, transformando-se na base do conhecimento social das organizações e convertendo conhecimento pessoal em temas disponíveis para outras pessoas. Assim, a partir de conversas podem-se explorar novas ideias e refletir sobre pontos de vista alheios. Von Krogh et al. (2001) sugerem o desenvolvimento dos quatro princípios norteadores do gerenciamento das conversas, assim demonstrados:

- Estimular ativamente a participação: um gerente de conversas agindo como mediador do grupo, incentivando, facilitando e garantindo a participação de membros desejáveis no debate e seus requisitos;

- Definir regras de etiquetas para conversas: estabelecimento de regras para que o grupo possa interagir de maneira mais construtiva e produtiva;

- Editar as conversas de maneira apropriada: gerenciamento das conversas no sentido da criação de compreensão quantos aos conceitos, convergindo e reduzindo esse repertório a alguns conceitos-chave; 
- Fomentar a linguagem inovadora: uma linguagem criativa com atributos lúdicos, vívidos e ricos de significado.

c) Mobilizar os ativistas do conhecimento - este processo estimula a atuação das pessoas que iniciam e coordenam os processos de criação de conhecimento. Assim, no começo do processo de criação, os ativistas do conhecimento atuam como facilitadores na criação e justificação de conceitos e desenvolvimento de protótipos. 0 ativismo do conhecimento é uma atribuição ampla, podendo concentrar-se em um departamento específico, em determinada pessoa ou situar-se em departamentos ou funções já existentes;

d) Criar o contexto adequado - estrutura interna adequada à interação entre as equipes. Esta fase está relacionada diretamente às estruturas organizações, fomentando relacionamentos sólidos e a colaboração eficaz e reforçando a interação entre conhecimentos tácitos e explícitos, a partir de fronteiras internas e externas à empresa. O desenvolvimento dessa percepção e da inovação como recursos para o sucesso competitivo leva à constatação de que as estruturas de organizações tradicionais necessitam de transformações, almejando a flexibilidade e adaptabilidade frente aos novos desafios propostos por atividades de negócio em um mundo onde as fronteiras são mais tênues, os relacionamentos mais complexos e o ambiente competitivo mais fluido;

e) Globalizar o conhecimento local - fazer com que ele seja disseminado nos diversos níveis da organização, constituindo-se em um grande desafio e em uma das maiores responsabilidades dos gerentes corporativos e locais, que necessitam manter profunda cooperação. Assim, a transferência de conhecimento é o foco da globalização do conhecimento local, porém, deve-se ter consciência de que mesmo um conhecimento documentado em detalhes de forma explícita, quando remetido a uma equipe destinatária encarregada de reproduzi-lo com exatidão em outro âmbito, passará por uma recriação.

Escrivão, Nagano e Escrivão Filho (2011), citando o trabalho de Von Krogh et al. (2001), demonstram que a organização deve oferecer capacitadores necessários para que o indivíduo, no grupo, crie conhecimento organizacional a partir de cinco condições: i) a intenção organizacional (definida como a aspiração de uma organização às suas metas); ii) a autonomia aos membros da organização (que introduz oportunidades inesperadas e possibilita a automotivação dos indivíduos para a criação de conhecimento); iii) flutuação e caos criativo (que estimulam a interação entre a organização e o meio ambiente externo, possibilitando a exploração da ambiguidade, da redundância e dos ruídos dos sinais ambientais, e aprimorando seu sistema de conhecimento); iv) redundância (informações que transcendem as exigências operacionais imediatas dos membros da organização, aumentando o volume de informações a serem processadas) e; v) variedade de requisitos dos membros da organização.

O Quadro 2 mostra os capacitadores e as respectivas contribuições para as fases da criação do conhecimento segundo Von Krogh et al. (2001 p. 18): 
Quadro 2 - Capacitadores para o conhecimento e as fases da criação do conhecimento.

\begin{tabular}{|l|c|c|c|c|c|}
\hline $\begin{array}{c}\text { Capacitadores do } \\
\text { conhecimento }\end{array}$ & $\begin{array}{c}\text { Compartilhamento } \\
\text { do conhecimento } \\
\text { tácito }\end{array}$ & $\begin{array}{c}\text { Criação } \\
\text { de } \\
\text { conceitos }\end{array}$ & $\begin{array}{c}\text { Justificação de } \\
\text { conceitos }\end{array}$ & $\begin{array}{c}\text { Construção } \\
\text { de protótipos }\end{array}$ & $\begin{array}{c}\text { Nivelação } \\
\text { do } \\
\text { conhecimento }\end{array}$ \\
\hline $\begin{array}{l}\text { 1) Instilar a visão } \\
\text { do conhecimento }\end{array}$ & $\mathrm{XX}$ & $\mathrm{XX}$ & $\mathrm{XX}$ & $\mathrm{XX}$ & $\mathrm{XX}$ \\
\hline $\begin{array}{l}\text { 2) Gerenciar as } \\
\text { Conversas }\end{array}$ & $\mathrm{X}$ & $\mathrm{X}$ & $\mathrm{X}$ & $\mathrm{XX}$ \\
\hline $\begin{array}{l}\text { 3) Mobilizar os } \\
\text { ativistas do } \\
\text { conhecimento }\end{array}$ & $\mathrm{X}$ & $\mathrm{X}$ & $\mathrm{XX}$ & $\mathrm{X}$ & $\mathrm{XX}$ \\
\hline $\begin{array}{l}\text { 4) Criar o } \\
\text { contexto adequado }\end{array}$ & & & & & $\mathrm{XX}$ \\
\hline $\begin{array}{l}\text { 5) Globalizar o } \\
\text { conhecimento } \\
\text { local }\end{array}$ & & & & & \\
\hline
\end{tabular}

Fonte: Braga; Neves; Vasconcelos (2013) e Von Krogh; Nonaka; Ichijo (2001)

Legenda: $\mathrm{X}$ significa menor intensidade, $\mathrm{XX}$ significa maior intensidade.

Segundo Pereira (2014, p. 74), o modelo de Von Krogh et al. (2001) evidencia que:

A criação de um contexto capacitante baseado nos cinco capacitadores [...], como apresentado pelos autores citados, são passos para se concretizar uma gestão organizacional do conhecimento, tendo como pressuposto a constatação de que uma organização não cria conhecimento por si só (PEREIRA, 2014, p. 74).

Como parte da criação do conhecimento, Von Krogh et al. (2001) afirmam que um panorama capacitante pode contribuir para esse desenvolvimento, podendo ser físico, virtual, mental ou os três ao mesmo tempo, pois o conhecimento, diferentemente de dados e informações, depende muito desse panorama. Portanto, a organização deve oferecer um cenário apropriado que propicie e facilite a criação do conhecimento, pois o conhecimento não pode ser criado sozinho, ele precisa de um lugar que dê significado à informação por meio da interpretação. Requer um cenário compartilhado, dinâmico e interativo, que transcende tempo, espaço e limites organizacionais e que não limite a interação.

Dentre muitas pesquisas consideradas para a construção deste trabalho, foram identificadas na literatura publicações recentes utilizando o modelo de Von Krogh et al. (2001), em que os pesquisadores avaliaram o contexto capacitante e os capacitadores do conhecimento, como: Braga et al. (2013), Carvalho et al. (2013), Silva (2013), Gomes (2014) e Pereira (2014).

\section{PROCEDIMENTOS METODOLÓGICOS}

Quanto aos fins, esta pesquisa se caracteriza como descritiva, a qual, segundo Gil (2002), tem como objetivo primordial: a descrição das características de determinada população ou fenômeno ou o estabelecimento de relações entre as variáveis. A abordagem escolhida foi a qualitativa, que visa a qualificar os resultados obtidos através do um estudo de caso único como técnica de pesquisa. Para Creswell (2009, p.15), a pesquisa qualitativa pode ser definida como: 
Um processo de investigação e entendimento baseado em tradições de investigação metodológicas que exploram o problema humano e social. 0 pesquisador constrói um quadro complexo e holístico, analisa palavras, reporta detalhadamente as visões de informantes e conduz o estudo em um campo natural (CRESWELL, 2009, p.15).

Alencar (1990) assevera que a pesquisa qualitativa visa compreender os fenômenos e suas consequências por meio da interpretação, possibilitando, dessa maneira, a emergência dos significados, da esfera simbólica e do desenvolvimento das intencionalidades, bem como o aprofundamento no fato pesquisado em busca da compreensão da diferença. Essa atitude fornece abertura para a subjetividade e, consequentemente, possibilita o questionamento do pressuposto da neutralidade científica, fornecendo detalhes profundos muitas vezes encobertos pela abordagem quantitativa. Para Richardson (1999), a pesquisa qualitativa caracteriza-se pela condição de descrever a complexidade de determinado problema, analisar a interação de certas variáveis e compreender e classificar processos dinâmicos vividos por grupos sociais.

Outro fato importante na pesquisa qualitativa mencionado por Vieira e Zouain (2006) é que ela geralmente oferece descrições ricas e bem fundamentadas, bem como explicações sobre processos em contextos locais identificáveis. Além disso, ela pode auxiliar o pesquisador a avançar em relação às concepções iniciais ou a ter que revisar a sua estrutura teórica. Indiferentemente de uma natureza mais subjetiva, a pesquisa qualitativa oferece mais flexibilidade para o pesquisador para a adequação da estrutura teórica ao estudo do fenômeno administrativo e organizacional desejado.

Esta pesquisa utilizou o estudo de caso como método, haja vista que o trabalho foi realizado na Granja de Suinocultura DF Pork localizada na cidade de Faria Lemos, em Minas Gerais, no ano de 2015. A escolha da empresa está diretamente ligada a critérios de acessibilidade. Collis e Hussey (2005) observam que é por meio dos estudos de caso que a teoria existente é utilizada para entender e explicar o que está acontecendo. E relatam que uma unidade de análise é o tipo de caso ao qual estão interligados as variáveis ou fenômenos que estão sendo pesquisados e o problema de pesquisa, bem como os dados a serem coletados e analisados. Uma abordagem de estudo de caso implica uma única unidade de análise, que pode vir a ser uma empresa ou um grupo de trabalhadores, um acontecimento, um processo ou até mesmo um só indivíduo.

A Granja de Suinocultura DF Pork constitui-se em uma multiplicadora de matrizes e terminadores da Génetiporc do Brasil (empresa canadense), e está inserida nos mercados de Minas Gerais, São Paulo, Rio de Janeiro e Espírito Santo. Seu sistema de produção da unidade funciona em três sítios (no sítio 1, concentra-se a parte reprodutiva, com os setores de gestação, maternidade e central de produção de sêmen; no sítio 2 localiza-se a creche, com leitões desmamados; e no sítio 3 ocorre a fase de crescimento e terminação).

Para que a Granja de Suinocultura DF Pork gerencie todas as etapas de produção de suínos, desde a gestão zootécnica, econômica e de custo de produção, ela conta com o apoio de um software de gerenciamento. A Agriness S2 é uma plataforma para gestão da informação da produção de suínos que permite, de forma integrada, o gerenciamento zootécnico, econômico, de fábrica de ração, farmácia e almoxarifado. Tem como objetivo ser a principal ferramenta de gestão do suinocultor para a tomada de decisão técnica e estratégica dos negócios. Somente o diretor/sócio-proprietário, gerente administrativo e gerente geral fazem os lançamentos e as análises por intermédio da Agriness S2.

A granja contava, à época da realização da pesquisa (março e abril de 2015), com um total de 27 colaboradores no seu quadro efetivo e um consultor, distribuídos em: gerente

Perspectivas em Gestão \& Conhecimento, João Pessoa, v. 8, n. 1, p. 20-43, jan./abr. 2018. 
administrativo, gerente comercial/logística, gerente geral, consultor médico veterinário e área técnico-operacional (três sítios e a fábrica de ração).

A coleta de dados limitou-se a pessoas que fazem parte da direção e aos demais profissionais integrantes. Assim, os sujeitos que constituem a unidade de observação pesquisada foram: um diretor/sócio-proprietário, um gerente geral, um consultor médico veterinário, cinco profissionais que atuam como auxiliar técnico operacional de cinco setores distintos da granja e um profissional do setor de produção da fábrica de ração.

Para Yin (2001), existem basicamente seis tipos de técnicas de coleta de dados em estudo de caso. Nesta pesquisa, foram utilizadas duas delas: entrevistas individuais em profundidade e observação participante. A escolha dessas técnicas de coleta de dados está diretamente relacionada ao tipo de pesquisa que se pretende realizar, sendo o objetivo perceber a compreensão dos profissionais atuantes e da direção, acerca dos conceitos sobre conhecimento, contexto capacitante e criação de conhecimento organizacional na granja. Gil (2002, p. 115) considera a entrevista uma técnica de coleta de dados "que envolve duas pessoas numa situação face a face em que uma delas formula questões e a outra responde".

Para melhor direcionamento das entrevistas, foi utilizado um roteiro semiestruturado, baseado em Pereira (2014), cujo foco concentrou-se em captar a percepção dos profissionais atuantes na granja e direção, a fim de se investigar a existência de capacitadores e se funcionam para a criação do conhecimento organizacional, segundo o modelo de Von Krogh et al. (2001).

Outro método utilizado foi a observação participante, a partir do qual, segundo Collis e Hussey (2005), o pesquisador fica completamente envolvido com os participantes e com os fenômenos que estão sendo investigados. Marconi e Lakatos (2000) esclarecem que a observação participante não utiliza instrumentos como questionários. Dessa forma, o alcance dos resultados almejados na pesquisa dependerá exclusivamente do pesquisador, como habilidade, flexibilidade, aspecto emocional, profissional e ideológico. Roesch (2005) destaca que nesse tipo de observação o pesquisador tem permissão para realizar sua pesquisa na empresa e todos sabem a respeito de seu trabalho. Com esse método, o pesquisador tem a capacidade de analisar, em detalhes, os eventos, descrever o que e de que forma aconteceu Neste trabalho, um dos autores é também gestor da DF Pork, o que lhe permitiu interpretar os dados coletados com maior precisão, traduzindo as opiniões qualitativas dos entrevistados à luz da realidade da organização.

\section{APRESENTAÇÃO E ANÁLISE DOS RESULTADOS}

\subsection{Perfil dos sujeitos da pesquisa}

Apenas como forma de caracterização dos participantes da pesquisa, as nove entrevistas realizadas foram todas com representantes do sexo masculino. Em relação à formação acadêmica, o diretor possui pós-graduação, o consultor médico veterinário possui nível superior completo e o gerente geral possui curso técnico. Os demais cursaram parte do ensino fundamental (quatro entrevistados) e ensino médio (dois entrevistados). Quanto ao tempo de serviço, os entrevistados distribuem-se entre membros novatos com até cinco anos (cinco entrevistados) e membros experientes com sete anos ou mais nos setores. 
Quadro 3 - Perfil dos sujeitos da pesquisa

\begin{tabular}{|c|c|c|c|c|c|}
\hline \multirow{2}{*}{ Nome } & Setor & Subsetores & Idade & $\begin{array}{c}\text { Tempo de } \\
\text { serviço no } \\
\text { setor }\end{array}$ & Formação \\
\hline Entrevistado 1 & Diretor/sócio & - & 50 anos & 07 anos & Pós-graduado em Economia \\
\hline Entrevistado 2 & Gerente geral & - & 36 anos & 07 anos & Técnico em Agropecuária \\
\hline Entrevistado 3 & $\begin{array}{c}\text { Consultor méd } \\
\text { veterinário }\end{array}$ & - & 52 anos & 04 anos & $\begin{array}{c}\text { Pós-graduado em Medicina } \\
\text { Veterinária }\end{array}$ \\
\hline Entrevistado 4 & Sítio 1 & Reprodução & 45 anos & 05 anos & Ensino fundamental incompleto \\
\hline Entrevistado 5 & Sítio 1 & Gestação & 22 anos & 04 anos & Ensino médio \\
\hline Entrevistado 6 & Sítio 1 & Maternidade & 37 anos & 07 anos & Ensino médio \\
\hline Entrevistado 7 & Sítio 2 & Creche & 47 anos & 03 anos & Ensino fundamental Incompleto \\
\hline Entrevistado 8 & Sítio 3 & Terminação & 51 anos & 03 anos & Ensino fundamental \\
Incompleto
\end{tabular}

Fonte: Adaptado pelos autores, de Granja DF Pork (2015)

\subsection{Perspectivas quanto aos conceitos de informação e conhecimento}

Primeiramente, buscou-se captar a perspectiva dos entrevistados quanto aos conceitos de informação e conhecimento, segundo os marcos teóricos conceituais que deram sustentação a este trabalho, como Nonaka e Takeuchi (1997), Setzer (1999), Probst et al. (2002), Davenport e Prusak (2003), Alvarenga Neto (2005) e Choo (2006).

O entrevistado 1 relatou a importância de informações claras e objetivas, pois compõem um conjunto de dados que permitem o conhecimento para a tomada de decisões. $E$ que o conhecimento é o que se aprende das informações. Essa mistura de experiências, quando inovadoras, permitem realizar o trabalho com mais precisão.

Nesse mesmo aspecto, o entrevistado 2, que atua junto à direção da granja, enfatizou a importância das informações serem reais e precisas. Abordou sobre a manipulação de dados, que mascara informações e dificulta o conhecimento. E que para adquirir o conhecimento é necessário entender e analisar as informações.

Concordando que dados não podem ser manipulados, o entrevistado 3 falou da coleta de dados confiáveis, que as informações permitem medidas corretivas para o alcance de objetivos e, dessa maneira, o conhecimento adquirido pode ser o diferencial no mercado.

\footnotetext{
Como atuo na nutrição e manejo dos animais, é através da informação, [...] preciso enfatizar da coleta de dados confiáveis [...], que gera o conhecimento e me permite tomar medidas corretivas. O diretor quer resultados, é justo, porém se não houver uma boa comunicação com os profissionais, da importância dos dados zootécnicos precisos, eu não vou conseguir enxergar o problema a tempo (E3, q.1 e 2).
}

O entrevistado 4 percebe que a informação como conjunto de dados está presente na rotina do trabalho, pois, atuando como auxiliar técnico operacional, além do conhecimento adquirido com a prática, experiências e habilidades, a informação gera o conhecimento, mas defende a necessidade de acompanhamento.

Quando entrei na granja, havia um manejo, mas venho notando ao longo dos anos certas mudanças, porém não me passam tão claramente as coisas. Há 1 ano atrás, entrou um novo gerente de setor, que mal sabia me passar

Perspectivas em Gestão \& Conhecimento, João Pessoa, v. 8, n. 1, p. 20-43, jan./abr. 2018. 
as coisas, tudo pela falta de comunicação, muito grosso com todos, só que eu sei que posso ajudar, porque aprendi muito estando todo esse tempo (E4, q.1).

O entrevistado 5 concorda que dados geram informações importantes e se alcança o conhecimento. $\mathrm{O}$ que se absorve de experiências, ideias e práticas gera o conhecimento. Já o entrevistado 6 disse que a informação é a base inicial para se chegar ao conhecimento. Sem informação não há como desenvolver o conhecimento. Acredita, ainda, que o conhecimento adquirido pode ajudar e muito nos resultados esperados da granja, mas é imprescindível gerenciá-lo, pois é um recurso a mais para a tomada de decisão.

O entrevistado 7 também não tem dúvidas de que a informação obtida gera conhecimento e que pode colaborar na rotina de trabalho, mas ressalta que a experiência e prática do dia a dia é muito importante e não pode ser isolada dos dados mensuráveis. "Eu acho que ter regras e normas para serem seguidas são aceitáveis, mas quando a gente coloca a mão na massa é um pouco diferente e isso pode ajudar também pra melhorar os resultados" (E7 q.1 e 2).

A relação de informação e conhecimento para os entrevistados 8 e 9 também não foge dos relatos dos entrevistados 1 a 7, quando argumentam sobre a importância dos dados serem confiáveis, gerarem informações necessárias e algumas vezes precisarem ser interpretados com mais detalhamentos. $O$ entrevistado 9 declara que a nutrição animal é muito cara, precisa de resultados satisfatórios e as informações passadas e adquiridas geram conhecimento, porém na produção de ração pouco pode acrescentar seus conhecimentos, porque existem fórmulas rigorosas dos insumos de acordo com o consultor médico veterinário.

Por meio de uma das falas do entrevistado 2, observou-se e constatou-se uma situação bastante importante e preocupante para a granja. No setor sítio 1, maternidade, onde os partos são realizados, existe grande preocupação com a temperatura corporal dos recémnascidos. Com isso, existe uma área de refúgio chamada 'escamoteador', onde esses recémnascidos se aquecem em temperatura controlada e muito favorável nos primeiros dias de vida. Essas áreas, além de aquecer, evitam possíveis esmagamentos ocorridos pelas próprias matrizes, já que os mesmos se encostam às porcas a fim de se manterem aquecidos. Essas porcas, ao se levantarem para se alimentarem ou beberem água, deitam-se e acabam esmagando os leitões. O método utilizado nesses escamoteadores são lâmpadas incandescentes de 220 volts de 100 watts. Porém essas lâmpadas já não estão sendo produzidas mais no mercado, causando grande preocupação para a granja estudada. 0 depoimento do entrevistado 2 transpareceu um conhecimento tácito bastante aprofundado sobre a questão, em que suas experiências vividas na granja por muito tempo.

Todavia, existe uma possibilidade de solução para esse problema registrado por um dos pesquisadores a partir da conversa com o entrevistado 2. Uma nova estratégia, como o uso de resistência elétrica, pode ser uma solução. Apesar do alto custo de energia, é a única opção no momento e pode viabilizar o lucro da granja no futuro. Sem esse aquecimento, aumenta-se o índice de perdas dos recém-nascidos, pelo esmagamento e ainda por perda de desempenho. Eles nascem com energia corporal e para mantê-la necessitam do leite materno e da fonte de calor, que são os escamoteadores, principalmente à noite, quando a temperatura cai em mais intensidade. Os colaboradores são orientados a conduzir esses recém-nascidos várias vezes ao dia entre os três primeiros dias de vida para a área de refúgio até que os mesmos identifiquem esse ambiente como o mais favorável. Passados 21 dias são desmamados e conduzidos ao setor sítio 2 Creche.

Perspectivas em Gestão \& Conhecimento, João Pessoa, v. 8, n. 1, p. 20-43, jan./abr. 2018. 


\subsection{Perspectivas quanto às práticas utilizadas para a criação do conhecimento organizacional}

Ao serem questionados sobre o compartilhamento de seus conhecimentos visando a criação do conhecimento organizacional, os entrevistados 1, 2 e 3 descreveram que criam situações, como reuniões, para compartilhamento de suas ideias e experiências, que são sempre registradas em suas anotações particulares para mais questionamentos e próximas reuniões, que são contínuas e com metas a cumprir. Outro meio usado para análise em reuniões é pela plataforma da Agriness S2, utilizada para lançamentos de dados mensuráveis que permitem detalhamento aprofundado e para geração de recurso organizacional com máxima eficácia. Os entrevistados 2 e 3, que também atuam no nível operacional da granja, compartilham informações para os demais, com a finalidade de se obter resultados e metas propostas em reuniões com o entrevistado 1.

Ainda o entrevistado 3 realça que, além do compartilhamento dos conceitos e informações, suas visitas periódicas na granja são registradas em um relatório de visita técnica, o qual é entregue ao entrevistado 1 . Nesse relatório constam observações percebidas durante a visita técnica, com propostas de programação de vacinas, medicação via ração, análise de dados como avaliação de consumo de ração pelas matrizes e custo de leitões desmamados, finalizando com algumas recomendações.

Quanto aos demais entrevistados, todos fazem menções diversificadas. $O$ entrevistado 4 opinou defender a necessidade de acompanhamento nas informações mas, mesmo registrando o que acha pertinente, não consegue ter feedback. Com isso, o compartilhamento não acontece de forma que se obtenha um resultado positivo.

Eu tenho o hábito de registrar aspectos interessantes, mas nem sempre consigo um resultado positivo, pois não depende só de mim. Devo mencionar que a falta de comunicação e o interesse próprio de alguns torna mais difícil a possibilidade de se chegar a isso (E4, q.4).

O entrevistado 5 descreve, com menos detalhes, que sempre que vê algo diferente, presta atenção, mostra aos demais colegas (repasse de conhecimento tácito) e que sente a necessidade de mais esclarecimentos, mais confiabilidade em suas ideias, podendo ajudar seus colegas e seu setor a atingir resultados. Os entrevistados 6,7 e 8 argumentam que a rotina de trabalho é sempre dentro das normas, que procuram colaborar e compartilhar suas experiências quando pertinentes, mas não há registros oficializados, somente as informações pretendidas. E acreditam que se pudessem registrar dados que fogem das normas, de alguma forma poderiam gerar informações e, consequentemente, conhecimento.

O entrevistado 9 identifica que há compartilhamento com demais colegas, pois se trata da produção de ração para os animais. E como existe consumo diário e a nutrição tem medida com fórmulas que não podem ser alteradas, não encontra possibilidade para informações a partir de diálogo aberto e críticas construtivas. Percebe como dificuldade ter iniciativas próprias, mas tem consciência de que existem normas e regras.

Uma questão observada e com menções importantes do entrevistado 2 é sobre a reposição de matrizes numa suinocultura. A leitoa de reposição é uma categoria de extrema importância no sistema de produção de suínos, pois se trata das fêmeas que serão futuras matrizes responsáveis pelo fornecimento de cevados. Uma granja precisa trabalhar com reposição de matrizes de $40 \%$ ao ano, com máximo de tolerância de sete ciclos, pois a vida útil produtiva da fêmea suína é invariavelmente menor do que o desejável. Na granja avaliada com um plantel de 950 matrizes, o ideal seria a inclusão de 380 novas matrizes por ano e descarte de todas as matrizes classificadas como involuntárias (biológicas) ou voluntárias (econômicas).

Perspectivas em Gestão \& Conhecimento, João Pessoa, v. 8, n. 1, p. 20-43, jan./abr. 2018. 
As remoções voluntárias são promovidas por decisão gerencial de caráter técnico e/ou econômico, como baixa produtividade individual e idade avançada.

A granja, na sua fundação, era multiplicadora de matrizes e terminadores da Génetiporc do Brasil, mas por motivos econômicos tornou-se uma granja comercial, porém ainda manteve genética que possibilita reposição do próprio plantel. Por descuido do setor reprodutivo, não houve cobertura genética. Os relatos alegaram a troca de responsáveis no setor como justificativa, mas foi observado um ponto de suma importância, que foi a falta de disseminação de dados importantes e seus conhecimentos aos demais colaboradores da granja, inclusive ao diretor/sócio-proprietário, colocando a granja em estado de alerta no equilíbrio da sua produção. Identificou-se que as etapas de conversão do conhecimento de Nonaka e Takeuchi (1997) que geram a espiral do conhecimento não se perpassam em seu processo na granja estudada. O conhecimento tácito desses responsáveis no setor não era compartilhado, o que gerou inúmeros problemas. Atualmente a granja passa por período bastante conturbado com a saída dos mesmos. A granja não trabalhou com o protocolo de reposição, reduzindo, assim, seus índices produzidos no manejo.

Segundo o entrevistado 2, a granja vem procurando trabalhar essa área afetada visando à reposição futura do plantel, porém os obstáculos são inúmeros. Verificou-se que uma decisão foi tomada em junho/2015 reativando a cobertura genética em julho/2015 e os partos referentes a essas coberturas iniciaram-se em novembro/2015. No entanto, essas matrizes precisam de 220 dias de idade para estarem aptas para inseminação, isto é, os resultados serão a longo prazo, pois passariam por mais 114 dias de gestação. Após esse período de gestação, os recém-nascidos precisarão de 150 dias de vida para serem comercializados com peso médio de $100 \mathrm{~kg}$ e só a partir daí começar a obter resultados com o equilíbrio da produção.

O diretor/sócio-proprietário está ciente do caso, porém inferiu-se que o entrevistado 2 é provido de alto conhecimento, de onde se observa a continuidade da ausência de compartilhamento e disseminação, por motivos de falta de aceitação e nivelação de conhecimento, o qual geraria muitos benefícios para a organização. Ficou em evidência que isso acontece e passa por todas as fases da criação do conhecimento, tornando nítidos possíveis problemas futuros com a saída desse entrevistado, caso ela ocorra.

\subsection{Perspectivas quanto aos capacitadores para a criação do conhecimento organizacional}

O entrevistado 1 declara que em reuniões com os entrevistados 2 e 3 aborda os objetivos desejados e gerencia as conversas, de forma a filtrar melhor os interesses; que aceita opiniões, que são sempre analisadas e, se pertinentes, colocadas em prática. Cita a existência de uma visão de conhecimento e que os demais entrevistados estão cientes dela. Trata de forma clara e objetiva críticas construtivas e acredita num profissionalismo capaz de gerar resultados.

Os entrevistados 2 e 3 confirmam e dão continuidade às conversas com a diretoria, para melhor compreensão dos objetivos e, assim, poderem repassar aos setores distintos. Porém, nem sempre estão de acordo com algumas questões tratadas nas reuniões com o entrevistado 1 - comenta o entrevistado 2 -, pois a prática, em algumas vezes, se distancia da teoria. Complementa que criar um cenário adequado aos entrevistados 4, 5, 6, 7, 8 e 9 requer excelência em comunicação, na linguagem, em estimular e, acima de tudo, fazer os mesmos entenderem o processo. Acredita que antes do "saber fazer" vem o "ensinar a fazer" e o "por que fazer". Na sua percepção a execução das tarefas precisa ser bem esclarecida, de modo a agregar valor.

Perspectivas em Gestão \& Conhecimento, João Pessoa, v. 8, n. 1, p. 20-43, jan./abr. 2018. 
São pessoas simples, com pouca leitura, que executam suas tarefas conforme é pedido, que muitas vezes não conseguem enxergar mais a frente, acham que limpar as baias e alimentar os animais de tempo a tempo é o suficiente, mas não percebem que podem ajudar mais, por exemplo, quando uma simples chupeta para de sair água, [...] eles não entendem que a borracha pode ter soltado ou outra simples coisa e que mesmo dando a hora de ir embora, não podem deixar aquela chupeta sem água, eles não conseguem compreender a importância de ir embora, mas sabendo que tudo está funcionando perfeitamente. Mas pra isso, eles precisam entender o porquê, pra que serve, o que vai atrapalhar se faltar água. Isso na teoria é fácil discutir em reuniões, quando é falado que não pode faltar água, mas na prática não é tão simples assim, envolve um forma de sentido das coisas e fazer com que essas pessoas, com pouca leitura, entendam que não é fácil mesmo. Muitas tardes e, outras vezes, noites, vou embora pra casa chateado com essas reuniões cansativas, além de inúmeros problemas que preciso resolver, porque não tive ninguém que tomasse a frente pra ajudar (E2, q.7,8 e 9).

O entrevistado 4 percebe certa dificuldade na comunicação com os entrevistados 1 e 2. Acredita que promover atividades seria bastante estimulador para eventuais conversas. Que treinamentos poderiam facilitar a execução das tarefas, as confraternizações, apesar de alguns não aproveitarem o momento, que poderia ser um meio de conhecer os demais colegas pela descontração e amizade, gerando posteriormente satisfação nos trabalhos em equipe, favorável à obtenção de resultados.

Ainda nessa linha, o entrevistado 2 discorre:

Sempre que dá, fazemos uma simples confraternização, você mesmo nos ajudou a organizar, porém, não sei o que acontece, falta boa parte dos colegas. Eu até acredito que ficam envergonhados, tem lá o jeito simples deles, eu respeito, mas é difícil demais agradar as pessoas. Eu como gerente, procuro ser o mais simples, educado, zeloso com minhas palavras, esse é o meu jeito, fui criado na zona rural, aprendi com a simplicidade das coisas a viver e não quero mudar nada em mim, mas sinceramente, como as pessoas são diferentes e difíceis! Muitas vezes penso que matar um porco e dividir as peças entre eles deve ser melhor do que convidá-los para uma confraternização (E2, q.10).

O entrevistado 5 confirma que já houve incentivo em treinamentos, inclusive conheceu outra granja, mas isso ocorreu bem no início da sua admissão, não existindo mais possibilidade de treinamentos, além das informações passadas pelo entrevistado 3 . Mas o mesmo faz visitas à granja em datas programadas, o que impede melhor nivelamento de conhecimento diário. $O$ entrevistado 6 reconhece não haver confraternizações e treinamentos, que fazem falta, porque acredita na construção de um ambiente de trabalho favorável. "Através dessas atividades, pode-se construir um ambiente bem melhor. Para mim, o local de trabalho é a segunda casa, às vezes passo mais tempo no trabalho do que na minha casa" (E6, q.10).

Os entrevistados 7, 8 e 9, citam ter bom convívio com os colegas, não se queixam da orientação da gerência, apesar do nivelamento do conhecimento não ser o esperado. Percebem o compartilhamento de suas ideias e experiências e se sentem bastante estimulados e motivados, quando são aceitas. 


\section{DISCUSSÃO DOS RESULTADOS}

A partir da apresentação e análise dos resultados obtidos, observou-se, quanto à percepção dos conceitos de informação e conhecimento por parte dos entrevistados, unanimidade de que os dados devem ser claros, objetivos, confiáveis, sem manipulações, para que haja precisão nas informações e, consequentemente, conhecimento. Por se tratar de uma granja de suinocultura, os dados zootécnicos são de suma importância para a tomada de decisão do diretor/sócio-proprietário, bem como do consultor médico veterinário, responsável pela nutrição animal e manejo, e associado ao gerente geral, responsável pelo nível operacional. Ressalta-se a importância do gerenciamento das informações e do conhecimento; entretanto, observou-se que, apesar das experiências diárias, quando pertinentes, serem favoráveis para a criação do conhecimento, não há reformulação e reapresentação do conceito. Essas percepções associam-se bem ao aspecto de uma das cinco fases do modelo proposto por Von Krogh et al. (2001), que apresenta o compartilhamento do conhecimento tácito via socialização.

Quanto à percepção dos sujeitos da pesquisa referentes às práticas utilizadas na granja para a criação do conhecimento organizacional, tem-se que, apesar de alguns entrevistados terem mencionado o compartilhamento do conhecimento tácito para o explícito, a maioria argumentou sobre a dificuldade da aceitação de suas experiências, por conta das normas e regras existentes na granja, aludindo que não há diálogo aberto e críticas construtivas para um novo protótipo.

Quanto à existência dos capacitadores na granja para a criação do conhecimento organizacional, o estudo indicou a existência de quatro dos cinco capacitadores de Von Krogh et al. (2001) - instilar a visão do conhecimento, gerenciar conversas, mobilizar os ativistas do conhecimento e criar o contexto adequado. Entretanto, estes capacitadores são percebidos no nível individual, através de práticas de conversão do conhecimento isoladas, mas não em nível organizacional.

Quanto ao primeiro capacitador, que é instilar a visão do conhecimento (tornar nítida a visão corporativa para melhor aproveitamento do conhecimento), todos os entrevistados souberam interpretar a pretensão da granja nos negócios. Porém, identificou-se que, apesar de todos compreenderem os objetivos da granja, é nítida uma lacuna de como melhorar os resultados a partir do nivelamento do conhecimento. Muitos entrevistados acreditam que mais informações podem gerar conhecimento e gostariam de participar mais ativamente com suas experiências e idéias, de forma a agregar valor à granja.

Quanto ao segundo capacitador, gerenciar as conversas por meio de reuniões e relatórios, os entrevistados 1,2 e 3 afirmam que o compartilhamento de conhecimentos é bem identificado e de forma estratégica com os recursos disponíveis. Porém, verificou-se, a partir da observação participante, que parte dos entrevistados não pode compartilhar suas experiências, e que a pouca comunicação que há na granja é precária, criando um ambiente em desarmonia.

Quanto ao terceiro capacitador para a criação do conhecimento, criar o contexto adequado (estrutura interna adequada à interação entre as equipes), parte dos entrevistados reconhece a importância de treinamentos e confraternizações, o que não acontece na granja, e da necessidade de um ambiente de trabalho mais feliz, já que passam mais tempo no trabalho, além de ser um ambiente que requer adaptação por conta do mau odor e insanidade.

O quarto capacitador apresenta um facilitador para a criação do conhecimento organizacional, que é globalizar o conhecimento local, característica dos gerentes corporativos e locais. Os entrevistados 2 e 3 têm como foco esse capacitador, já que atuam junto ao operacional com objetivos e metas traçadas em reuniões com o entrevistado 1 . 0 entrevistado

Perspectivas em Gestão \& Conhecimento, João Pessoa, v. 8, n. 1, p. 20-43, jan./abr. 2018. 
2 considera difícil disseminar o conhecimento quando comparada a teoria com a prática, mas busca, com suas experiências, adequar-se aos níveis da organização e que normalmente as relações são fontes de cooperação.

\section{CONSIDERAÇÕES FINAIS}

O presente trabalho investigou os capacitadores para a criação do conhecimento, sob a ótica de Von Krogh et al. (2001), existentes no contexto organizacional da Granja de Suinocultura DF Pork, localizada na cidade de Faria Lemos, Minas Gerais. Dessa forma, com a pesquisa de campo e com base no objetivo proposto, foram identificados capacitadores para a criação do conhecimento no contexto organizacional da Granja de Suinocultura DF Pork, limitando-se apenas à inexistência de um capacitador, que é mobilizar os ativistas do conhecimento. Destaca-se, porém, que esses capacitadores existem em nível individual, através de práticas de conversão do conhecimento isoladas, mas não em nível organizacional.

Recomenda-se que a granja trabalhe no sentido de implementar práticas voltadas à construção do conhecimento organizacional, aproveitando-se da existência dos capacitadores em nível individual. Ressalta-se que esta recomendação, apesar de voltada à realidade empresarial estudada, pode ser replicada em outras organizações nas quais se identifique $o$ mesmo contexto, ou seja, de existência dos capacitadores em nível individual, mas não em nível organizacional.

Retomando as justificativas apontadas no início deste artigo, o presente trabalho e seus resultados, de fato, já puderam contribuir para o repensar dos processos referentes à Gestão do Conhecimento na granja DF Pork, a partir dos capacitadores propostos por Von Krogh et al. (2001), e a implementação de melhorias incrementais, conforme afirmação dos próprios sócios/proprietários, sendo esta uma contribuição gerencial aplicada importante. Por outro lado, este estudo contribuiu para a academia, ampliando o arcabouço teórico-empírico de um tema que tem ganhado representatividade nos campos da Administração e da Ciência da Informação, em especial.

Como limitações do trabalho, as análises apresentadas se referem ao estudo de caso em questão, não podendo ser generalizadas para outras empresas. Entretanto, o referencial teórico, os procedimentos metodológicos, a estrutura de análise das entrevistas qualitativas, e o uso da observação participante se mostraram adequados e atenderam aos objetivos propostos, caracterizando um método de pesquisa que pode ser utilizado em estudos futuros e/ou em outras organizações de setores e portes diferentes do caso em questão.

Como pesquisas futuras, recomenda-se a investigação do tema sobre capacitadores para a criação do conhecimento organizacional em outras realidades empresariais, bem como em outras localidades e regiões. Além disso, seria importante procurar medir, em nível quantitativo, as percepções dos colaboradores das empresas a respeito da existência (ou não) dos capacitadores nos contextos empresariais a serem estudados. Por último, recomenda-se também a realização de estudos longitudinais, buscando verificar mudanças no contexto empresarial estudado, a partir de uma primeira leitura sobre a existência (ou não) dos capacitadores para a criação do conhecimento, passando por um período de implementação de ações corretivas, e posteriormente, identificando possíveis mudanças e/ou melhorias na empresa a partir das intervenções realizadas.

\section{REFERÊNCIAS}

ALENCAR, J.C. Interpretação fenológica de espécies lenhosas de campina na Reserva Biológica de Campina do INPA ao norte de Manaus. Acta Amazônica, v.20, n.1, p.145-183, 1990.

Perspectivas em Gestão \& Conhecimento, João Pessoa, v. 8, n. 1, p. 20-43, jan./abr. 2018. 
ALVARENGA NETO, R.C.D. Gestão do conhecimento em organizações: proposta de mapeamento conceitual integrativo. 2005, 400f. Tese (Doutorado em Ciência da Informação) Programa de Pós-Graduação em Ciência da Informação, Escola de Ciência da Informação da Universidade Federal de Minas Gerais, Belo Horizonte, 2005.

ANGELONI, M.T. Organizações do conhecimento: infraestrutura, pessoas e tecnologias. São Paulo: Saraiva, 2002.

BEIRA, S.C.P.; SIQUEIRA, A.H.; FERNEDA, E.; PRADO, H.A. Ontologia como um artefato da arquitetura da informação para a representação do conhecimento organizacional. João Pessoa, Perspectivas em Gestão \& Conhecimento, v.7, n.2, p.122-159, jul./dez., 2017.

BEZERRA, C.A.; GUIMARÃES, A.J.R. O desempenho inovador de agências de publicidade e sua relação com a Gestão do Conhecimento e condições organizacionais de Inovatividade e Criatividade. João Pessoa, Perspectivas em Gestão \& Conhecimento, v.7, n.1, p.70-97, jan./jun., 2017.

BRAGA, C.R.A.; NEVES, J.T.R.; VASCONCELOS, M.C.R.L. Os capacitadores do conhecimento e suas contribuições para a criação do conhecimento numa organização do terceiro setor: estudo de caso da Junior Achievement de Minas Gerais. In: SIMPÓSIO INTERNACIONAL DE INOVAÇÃO E SUSTENTABILIDADE, 1.; SIMPÓSIO INTERNACIONAL DE GESTÃO DE PROJETOS, 2., Anais...., São Paulo/SP, 2013.

BUKOWITZ, W.R.; WILLIAMS, R.L. Manual de gestão do conhecimento: ferramentas e técnicas que criam valor para empresa. Porto Alegre: Bookman, 2002.

BUORO, G.; OLIVA, F.L.; SANTOS, S.A. Compartilhamento de conhecimento: um estudo sobre os fatores facilitadores do processo. In: SANTOS, S.A.; LEITE, N.P.; FERRARESI, A.A. (Orgs.). Gestão do conhecimento: institucionalização e instituições (pesquisas e estudos). Maringá (PR): Unicorpore, p.51-86, 2007.

CARVALHO JR., M. V.; VASCONCELOS, M. C. R. L.; TAVARES, M. C.; ZIVIANI, F. Contribuições da gestão do conhecimento para as estratégias de sobrevivência e avanço dos negócios em uma empresa familiar de médio porte. In: SIMPÓSIO INTERNACIONAL DE INOVAÇÃO E SUSTENTABILIDADE, 1.; SIMPÓSIO INTERNACIONAL DE GESTÃO DE PROJETOS, 2., Anais...., São Paulo/SP, 2013.

CHOO, C. W. A organização do conhecimento: como as organizações usam a informação para criar significado, construir conhecimento e tomar decisões. 2. ed. São Paulo: SENAC, 2006.

COLLIS, J.; HUSSEY, R. Pesquisa em Administração: um guia prático para alunos de graduação e pós-graduação. 2. ed. Porto Alegre: Bookman, 2005.

CRESWELL, J. W. Projeto de pesquisa: método qualitativo, quantitativo e misto. 3. ed. Porto Alegre: Bookman, 2009.

DA SILVA, S. L. Gestão do conhecimento: uma revisão crítica orientada pela abordagem da criação do conhecimento. Brasília, Ciência da informação, v.33, n.2, p.143-151. 2004.

Perspectivas em Gestão \& Conhecimento, João Pessoa, v. 8, n. 1, p. 20-43, jan./abr. 2018. 
DAVENPORT, T. H.; PRUSAK, L. Conhecimento empresarial: como as organizações gerenciam o seu capital intelectual. 13. ed. Rio de Janeiro: Elsevier, 2003.

ESCRIVÃO, G.; NAGANO, M. S.; ESCRIVÃO FILHO, E. A gestão do conhecimento na educação ambiental. Belo Horizonte, Perspectivas em Ciência da Informação, v.16, n.1, p.92-110, jan./mar., 2011.

FLEURY, M. T. L.; OLIVEIRA, J. R. Gestão estratégia do conhecimento. São Paulo: Atlas, 2001.

GIL, A.C. Métodos e técnicas de pesquisa social. 5. ed. São Paulo: Atlas, 2002.

GOMES, P. W. R. Uso de indicadores e capacitadores do conhecimento para a competitividade do Centro Universitário UNA. 2014. 97f. Dissertação (Mestrado Profissional em Administração). Pedro Leopoldo: Fundação Pedro Leopoldo, 2014.

GONÇALVES, S.F.R. Gestão do conhecimento: análise de práticas e ferramentas no âmbito da Administração Tributária de Minas Gerais. 2010. 161f. Dissertação (Mestrado Profissional em Administração). Pedro Leopoldo: Fundação Pedro Leopoldo, 2010.

GRANJA DF PORK. Granja de Suinocultura Duduta Ferreira Pork. Documento interno. Faria Lemos - MG, 2015.

KUNIYOSHI, M.S. Institucionalização da gestão do conhecimento: um estudo das práticas gerenciais e suas contribuições para o poder de competição das empresas do setor elétricoeletrônico. 2008. 210f. Tese (Doutorado em Administração) - Faculdade de Economia, Administração e Contabilidade da Universidade de São Paulo, São Paulo, 2008.

MAFRA PEREIRA, F. C. O processo de conversão do conhecimento em uma escola de atendimento especializado. Florianópolis, Encontros Bibli, v.20, p.38-52, 2005.

MARCONI, M.A.; LAKATOS, E.M. Metodologia científica. São Paulo: Atlas, 2000.

NAKANO, D.N.; FLEURY, A.C.C. Conhecimento organizacional: uma revisão conceitual de modelos e quadros de referência. Revista do Programa de Pós-Graduação em Engenharia da Produção da Universidade Federal do Rio Grande do Sul, Produto e Produção, v.8, n.2, p.1123, 2005.

NONAKA, I.; TAKEUCHI, H. Criação de conhecimento na empresa. 18a ed. Rio de Janeiro: Elsevier, 1997.

PEREIRA, A.A. O papel do contexto capacitante na construção do conhecimento organizacional: um estudo de caso sobre condições capacitadoras da gestão do conhecimento. 2014, 156f. Dissertação (Mestrado Profissional em Administração). Pedro Leopoldo: Fundação Pedro Leopoldo, 2014.

PROBST, G.; RAUB, S.; ROMHART, K. Gestão do conhecimento: os elementos construtivos do sucesso. Porto Alegre: Bookman, 2002.

Perspectivas em Gestão \& Conhecimento, João Pessoa, v. 8, n. 1, p. 20-43, jan./abr. 2018. 
REIS, M.E.A. Portal corporativo como ferramenta de gestão do conhecimento. $136 f$. Dissertação (Mestrado Profissional em Gestão da Informação e Comunicação em Saúde) Fundação Oswaldo Cruz, Rio de Janeiro, 2005.

RICHARDSON, R.J. Pesquisa social: métodos e técnicas. 3. ed. São Paulo: Atlas, 1999.

ROESCH, S.M.A. Projetos de estágio e de pesquisa em Administração: guia prático para estágios trabalhos de conclusão, dissertações e estudo de caso. 3. ed. São Paulo: Atlas, 2005.

SANTOS, M.J.N. Gestão de recursos humanos: teorias e práticas. Porto Alegre, Sociologias, ano 6, v.12, p.142-158, 2004.

SCHARF, E.R. Gestão do conhecimento aplicada ao marketing. Florianópolis: Visual Books, 2007.

SETZER, V.W. Dado, informação, conhecimento e competência. Rio de Janeiro, Data Grama Zero - Revista de Ciência da Informação, 1999. Recuperado de: http://www.dgz.org.br/dez99/ Art 01.htm. Acesso em 07 mar. 2015.

SILVA, M. Contribuições dos capacitadores do conhecimento e das estratégias de sobrevivência e avanço para o aumento da competitividade de uma empresa multinacional do setor alimentício. 2013. 148 f. (Dissertação Mestrado Profissional em Administração). Pedro Leopoldo: Fundação Pedro Leopoldo, 2013.

STEWART, T. Capital intelectual: a nova vantagem competitiva das empresas. Rio de Janeiro: Campus, 1998.

TERRA, J. C. C. Gestão do conhecimento: o grande desafio empresarial; uma abordagem baseada no aprendizado e na criatividade. 3. ed. São Paulo: Negócio, 2001.

TRINDADE, E. P.; MACEDO, M.; GAUTHIER, F. A. O.; BOTELHO, L. L. R.; LABIAK JUNIOR, S. Soluções de Gestão do Conhecimento para Pequenas e Médias Empresas (PME). João Pessoa, Perspectivas em Gestão \& Conhecimento, v. 6, Número Especial, p.189-203, jan., 2016.

VASCONCELOS, M. C. R. L. Cooperação universidade-empresa na pós- graduação: contribuição para a aprendizagem, a gestão do conhecimento e a inovação na indústria mineira. Tese (Doutorado em Ciência da Informação) - Escola de Ciência da Informação, Universidade Federal de Minas Gerais, 2000.

VASCONCELOS, M. C. R. L.; FERREIRA, M. A. T. O processo de aprendizagem e a gestão do conhecimento em empresas mineiras de vanguarda. In: ENCONTRO DA ASSOCIAÇÃO NACIONAL DOS PROGRAMAS DE PÓS-GRADUAÇÃO EM ADMINISTRAÇÃO, EnANPAD, n.26. Anais... Salvador, 2002.

VIEIRA, M. M. F.; ZOUAIN, D. M. (Orgs.). Pesquisa qualitativa em Administração. 2. ed. Rio de Janeiro: FGV, 2006.

VON KROGH, G.; NONAKA, I.; ICHIJO, K. Facilitando a criação do conhecimento. Rio de Janeiro: Campus, 2001.

Perspectivas em Gestão \& Conhecimento, João Pessoa, v. 8, n. 1, p. 20-43, jan./abr. 2018. 
YIN, R K. Estudo de caso: planejamento e métodos. Porto Alegre: Bookman, 2001.

Artigo recebido em 08/02/2017 e aceito para publicação em 19/01/2018 